\title{
VAN DRIE TOPPEN VAN HET ANTILLEN-MASSIEF
}

(Een orografische schets onzer Bovenwindsche eilanden)

DOOR

IR. F. S. LANGEMEYER

God heeft het zóó in de wereld gesteld, dat de mensch zich moeite moet getroosten om zijn zuiverste emoties te bereiken; doch niet de moeite zelve mag heerscheres worden.

Het zijn niet de dagen van warmte en zweet, als de zon fel en strak aan den hemel stond of bij wijlen de bezwangerde hitte onder een dicht wolkendek bleef hangen, die mij de herinnering aan onze West-Indische jaren zoo ontroerend maken en een sterk verlangen naar het vervlogene opwekken. Het zijn ook niet de avonden, die als van zelf de rust mèt de weldadig aangroeiende koelte brachten. Zelfs niet de majestueuze tropennachten met haar, de stilte accentueerend geruisch en geraas der millioenen insecten. Hoe mooi ook sommige nachten konden zijn, als de maan boven de heuvels achter de Vine-yard ${ }^{1}$ ) stond en alle voorwerpen met haar mysterieus licht overgoot, hun ontroering was te gemakkelijk.

Wat mij het hoogst ontroerde waren de prille ochtenden, als ik mij aan de rust ontrukt had: de jonge zon zette de naar het oosten gekeerde hellingen der bergen in een limpide licht, terwijl aan de overzijde de hellingen nog in schaduw gehuld waren. Wat dan de atmosfeer op den frisch ontwaakten mensch overbrengt, is een stemming, die slechts kan aanvoelen hij, die zulke tropenochtenden heeft doorleefd.

Ik herinner me als gisteren dien ochtend van Mei 1918, toen, op onze heenreis naar St. Maarten, de Estelle 2) in alle vroegte het

1) F. S. Langemeyer: Ver van 's werelds strijdgewoel. W.I.G., 22e jrg.

2) F. S. Langemeyer: „Eene reis naar St. Maarten in oorlogstijd". W.I.G., $19 \mathrm{e} \mathrm{jrg}$.

$$
-161-
$$


anker had laten vallen op de reede van Oranjestad, op St. Eustatius. Het Beneden-dorp lag daar achter het Westerstrand en vóór de steile kliffen, de varieerende lagen van achtereenvolgende erupties. Met daarboven, tusschen groen, de omtrekken der voorste gebouwen van het Boven-dorp. De Westelijke helling van de "Quill", tegen de zon in, lag nog in de schaduw.

Ik herinner me, op onze terugreis in Maart 1920, dien ochtend vóór de Fort-baai, de Zuidelijke der beide, naar mate de windrichting bevaren, ankerplaatsen van Saba. We waren des nachts aangekomen en het voor-anker-gaan had ons gewekt. Glorierijk ontwaakte de dag en de straten van de boven den einder rijzende zon gleden langs de steile, ontoegankelijke rotsen van die massale, in de „Piek" culmineerende, vulkaanruïne.

En dan, tusschen die beide reizen in, die zeldzame ochtenden -- want de hoogste stemming is ons slechts een enkele maal toegestaan - die zeldzame ochtenden, dat de stemming over mij wilde komen en over het uitzicht vanaf onze, op het Westen uitziende, voorgalerij op de naar ons toe gekeerde hellingen van de Westelijke heuvelreeks in de rechte stralen van de achter de oostelijke heuvels opkomende zon.

Recht vóór ons stond, te lood boven Philipsburg, de Fortberg en meer naar rechts stak de boven-omtrek van Sentry-hill en Mont-des-Accords tegen de lucht af als een opgebaarde doode, den „Dooden Man”. Nog meer naar het noorden, achter het groote zoutmeer, lag Williams-hill, op welks helling het plantagehuis van Madam's duidelijk te onderscheiden was. Naar links de Zuidpunt van het eiland en de rotsige landtong, waar, aan de seinpaal van het oude Fort Amsterdam, fier het rood, wit en blauw wapperde en nog steeds wapperen zal: een trouwe getuige van onveranderde souvereiniteit.

En dan de, in het milde ochtendlicht, zoo ontroerend mooie zee. De zee, die elken dag weer anders was en toch altijd de zelfde.

Soms, door een rimpeling van het water, of door een kleurschakeering, kon je de Proselyte-klip 1) zien, de gevaarlijke, steile, slechts 35 yards metende klip, die op 11/4 mijl recht bezuiden Fort-Amsterdam lag, en waarop maar 21/4 vadem 2 ) water stond.

En als we dan uit onze voorgalerij afdaalden naar het strand, zagen we, terwijl de visschers met hun conk-geblaas en geroep van

1) West-Indies Pilot II, 2e druk, blz. 82 .

2) 1 vadem $=1,83 \mathrm{~m}, 1$ zeemijl $=1855 \mathrm{~m}$. 
,ten jacks for a bit" de vroegte doorschalden, in het zuiden, glashelder en sereen, onze buren liggen: St. Kitts en St. Eustatius, en Saba.

De zee en de bergen..., zij zijn onafscheidelijk in mijn geheugen aan die ochtendstemmingen verbonden. De nabije bergen met hun grillige omtrekken en de in het verschiet liggende eilanden, die regelmatiger contourlijn vertoonden, misschien omdat, door de grootere afstand, alleen de groote lijn te zien was, maar toch ook omdat zij, door hun vulkanische opheffing, werkelijk van regelmatiger vorm waren. In statige en onbeweeg'lijke grootschheid stelden die bergen de rijzende lijn tegen de schijnbare overheersching van het waterpas der zee.

Schijnbaar, want de zee is slechts de vloeibare massa, die het bergmassief bedekt, waarvan de eilanden de, boven water uitstekende, toppen zijn. Drie toppen, St. Maarten, St. Eustatius en Saba hebben onze aandacht, omdat er nu eenmaal een deel van onze historie, een deel van ons zelf ligt.

Een muggenzifter moge zeggen: het zijn veel meer dan drie toppen, want althans St. Eustatius en St. Maarten hebben er elk een aantal. Goed, dan bedoel ik met mijn drie toppen de Piek, de Quill en de Mont-des-Accords, waar in 1648 het verdeelingsverdrag tusschen Franschen en Nederlanders werd gesloten. Drie toppen en hun omgeving.

$\mathrm{Ze}$ liggen op een interessant punt van het onderzeesche gebergte, onze drie toppen. Want hier is het ontmoetingspunt van de West-Oost gerichte, met Cuba en Jamaïca breed uit het vasteland uitspringende, en zich naar St. Maarten en St. Barth's toespitsende bergrug, die het, tot meer dan 2500 vaam diepe, bekken der Caraïbische zee in het noorden begrenst, met de Oostelijke wand van dat bekken, de concave, in hoofdzaak zuidnoord gerichte keten.

Zelfs de diepste plekken van de, het Caraïbische bekken omsluitende, bergwand - in de Anegadapassage, waar langs de Virginische eilanden 1100 vademen water staat - zijn nog een 2500 meter hooger dan de bodem van de kom. Tusschen de eilanden om en nabij St. Maarten, St. Eustatius en Saba, nabij het ontmoetingspunt der bergruggen dus, staat niet meer dan 450 vademen.

Toch bestaat er, geologisch gesproken, een grooter verschil tusschen de eilanden der beide, elkaar onder een hoek van ongeveer $90^{\circ}$ ontmoetende, bergketenen, dan tusschen de eilanden aan weerszijden der Anegada-passage. De eerste, de West-Oost 
gerichte bergketen, is van een prae-tertiaire opheffingslijn 1). Het oud-eruptieve hoofdgesteente is, in den opheffingstijd, ten deele overdekt met sedimentaire vormingen. De eilanden van de Zuid-Noord gerichten keten zijn meerendeels - enkele langs de Atlantische zijde van de gebogen lijn gelegen eilanden uitgezonderd - jonger. Zij zijn vulkanisch gevormd in het post-pliocene tijdperk. En ook daarin bestaat onderling nog weer verschil van ouderdom.

St. Maarten behoort tot de eerste groep, die der oude Antillen; Saba en St. Eustatius tot de jongere, vulkanische, groep, waarbij St. Eustatius dan nog weer jonger is dan Saba. Dit alles is gebleken uit het geologische onderzoek der gesteenten.

Alle drie verkeeren thans, volgens Molengraaff, in een periode van daling. Dit wordt onder meer geconcludeerd uit de omstandigheid, dat er practisch geen recente koraalafzetting boven de waterlijn te vinden is. Doch verder ook daaruit, dat in de breedere dalen de baaien zoo diep landinwaarts doorgedrongen zijn. Een voorbeeld daarvan is de Groote baai van St. Maarten, die, met het daarachter gelegen Zoutmeer één geheel vormt. Een bevestiging hiervan vond ik bij een drietal grondboringen in de zandplaat tusschen Baai en Zoutmeer, de bank waarop Philipsburg gebouwd is. Op 10 à 11 meter diepte onder den middelbaren zee-spiegel werd de oude landoppervlakte aangeboord. Daarboven het witte zand der jongere nederzettingen uit de zee en daaronder de verweeringsproducten der oudere gesteenten: een blauwe leemachtige, klei en een zeer donker gekleurd zand.

Reeds de uiterlijke gedaanten van St. Eustatius en Saba doen hunne vulkanische vorming onderkennen. De jongste dier vormingen, de hoofdvulkaan van St. Eustatius, die, naar den ronden krater of kuil, meestal ,the Quill" genoemd wordt, vertoont het zeer regelmatige uiterlijk van een afgeknotten kegel, met een helling van de beschrijvende lijn van $30^{\circ}$. Daaronder verflauwt de helling tot $20^{\circ}$. Slechts de opheffing van den White-wall ${ }^{2}$ ), met de daarvan afgestorte Sugar-loaf, en het parasitaire kratertje, Round-hill genaamd, zijn onregelmatigheden op de gladde, ten tijde van ons bezoek grootendeels met sisal begroeide, vulkaan wanden.

Het inwendige van de Quill, op $273 \mathrm{~m}$ boven zee gelegen, geeft

1) Dr. A. L. W. E. van der Veen: Artikel „Aardkunde” in de Encyclopaedie van N.W.I. (1917).

2) Dr. G. A. F. Molengraaff: De Geologie van het eiland St. Eustaius. (Academisch proefschrift Leiden 1886). 
met zijn steile, sombere, rotswanden - de hoogste top van den krater-rand is 601 meter boven zee, of $328 \mathrm{~m}$ boven den Quillbodem - en zijn tropische plantengroei, vol lianen en fantastische boom-vormen, een ongeloof'lijk sprookjesachtigen indruk. In een enkel uur doorvoelden we hier de geheele romantische sfeer, die we in onze jeugd beleefden in de wildernis-romans van Aimard en in de platen van Gustave Doré bij de Atala van Chateaubriand.

Ook de grilliger geteekende bergen ten noorden van de, door lavastroomen uit de Quill ontstane cultuurvlakte, het op 30 à 40 meter boven zee gelegen land- en tuinbouw-gebied in het midden van het eiland, waar de sea-island-cotten gekweekt werd, zijn van vulkanische, zij het oudere, formatie. De tot ruine verworden kraterrand loopt over de heuvels Bergje, Boven (293 m) en Gilboa. De hoefijzervormige kam, waarvan Signal-hill $(234 \mathrm{~m})$ de Oostpunt is, moet als een parasitaire krater worden beschouwd.

De hoofd-gesteenten van St. Eustatius zijn hoornblendeaugiet-andesiet en augiet-andesiet, met locale afwisselingen en hunne tuffen.

Vormt St. Eustatius de noordwestpunt van een berggroep, waarvan St. Kitts en Nevis de andere bovenzeesche toppen zijn, en waarvan de hellingen steil afloopen van 20 à 30 tot 450 vademen in het noorden, Saba ligt geheel op zich zelf. Een smalle, 360 vademen diepe, geul scheidt het eiland van de groote Sababank, waarop gemiddeld slechts 20 vâm water staat. Over een oppervlakte van $13 \mathrm{KM}^{2}$ - als Schiermonnikoog ${ }^{1)}$ - bereikt Saba, met de Piek, een hoogte van bijna 900 meter.

Ook Saba is een vulkaan-ruïne. De oude krater is hier niet zoo gemakkelijk te herkennen. De naam ,the Bottom" voor het hoofddorp getuigt van de vroegere meening dat de kleine, door steile tufwanden omringde, op 200 à $300 \mathrm{~m}$ boven zee gelegen, vlakte de krater was. Doch volgens latere opvatting ${ }^{2}$ ) is deze vlakte door erosie ontstaan.

Het duidelijkste voorbeeld van eruptie is de lavastroom op een deel der noord-oostelijke helling, die met het eilandje FlatPoint ${ }^{3}$ ) in zee is vooruitgeschoven. Het hoofdgesteente van Saba bestaat uit zulke lavastroomen van augiet- en van hoorn-

1) Uit een rapport van Gouverneur Barge (1890).

2) R. Sapper: ,Ein Besuch von St. Eustatius und Saba”, Zentralbl. t. Min. 1903.

3) J. W. Spencer: ,,On the Geol. and Phys. dev. of St. Chrystopher chain and Saba-banks, Quart. Journ. Geol. Soc. London 1901. 
blende-andesiet, met een zwavelvorming, eveneens aan de noordoostzijde, nabij Hell's gate. Deze zwavel zou exploiteerbaar zijn, als de vindplaats niet, op $110 \mathrm{~m}$ boven zee, aan een ongenaakbare kust lag.

St. Maarten eindelijk, waarvan het Nederlandsche deel een oppervlakte van $49 \mathrm{KM}^{2}$ heeft, is dus niet van vulkanische formatie. Het eiland bestaat uit een laag gedeelte in het Westen, rondom het Simsonbaai lagoen, en twee noord-zuid gerichte, door de Belle-Plaine van elkaar gescheiden, heuvelreeksen op het oostelijk $2 / 3$-deel. De waterscheiding van Middle-Region is een zuidelijke verhooging van de Belle-Plaine, alvorens deze in de diepe inham van Zoutmeer en Groote-Baai overgaat. Ook aan de noord-zijde heeft de vlakte zulk een inham: Anse de l'Embouchure met Fish-Pond.

Vanaf een punt, in de nabijheid der school van Middle-Region, heeft men noordwaarts een prachtig uitzicht op de Plaine en op de wederzijdsche heuvelketens. In vroeger eeuwen kon men hier het wuivende suikerriet aanschouwen 1). Dat is niet meer zoo. In onzen tijd was het, behalve wat katoen en voedingsgewassen, een met groote steenblokken bezaaide grasvlakte. Zulke rolsteenen liggen op vele hellingen van het eiland. Het zijn de harde deelen van het gesteente, waartusschen de zachtere, eerder verweerde, massa is uitgespoeld. In de Belle-Plaine komt het ouderuptieve hoofdgesteente van St. Maarten - kwarts-glimmerdioriet - aan de oppervlakte 2). De gesteenten der wederzijdsche heuvelreeksen zijn meest sedimentaire formaties uit den cretaceïschen tijd.

De Oostelijke keten, die bij Oyster-Pond begint en Zuidwaarts met een steile, witte rotswand - Point-Blanche - in zee eindigt, heeft als hoogste top de Naked-Boy (300 m). De Point-Blancheformatie - een kwarts-diabaas -- is kenmerkend voor het eiland. De hoogste toppen van de Westelijke reeks zijn Paradis (ruim 400 $\mathrm{m})$, op Fransch gebied, Flagstaff (386 m) en Sentry-hill, het voorhoofd van den Dooden Man (344 m). Ook de Mont-des-accords behoort er bij.

In tegenstelling met St. Eustatius en Saba, waar slechts diep uitgespoelde, steile, doch droge ,guts" worden aangetroffen, zijn er op St. Maarten drie stroompjes, die bijna voortdurend water

1) Dr. I. Dornseiffen: „Het eiland St. Maarten”. Tijdschr. Aardr. genootsch. 1883.

2) Dr. G. A. F. Molengraaff : „Het Geol. Verband t.d. W.I. eilanden” Handel. 1e Ned. Nat. en Geneesk. congres, Amsterdam 1887. 
bevatten. Het aardigste dezer beekjes is dat van het idyllische dal Cul-de-Sac, waar de plantage-huizen, te midden van het geboomte, liggen aan den voet van de steile wanden der Williams-, St. Peter-, en Sentry-heuvels. Ten zuiden van deze laatste volgt dan de Koolbaaiberg, in welks gesteente mangaan-erts voorkomt. In zijn hellingen is uitgehouwen de hooge weg naar Marigot, die zulk een wijd uitzicht biedt over de zee.

Zoo liggen daar dan, in storm en in zonneschijn, bij dag en bij nacht, doch ook in den helderen ochtend, als wachters tusschen hun makkers, onze drie eilanden ,,boven den Wind". Ze zijn klein en toch.... Wie er eenmaal woonde, diens hart blijft gebonden en diens geest trekt er telkens weer heen. Is dàt niet de charme van een eiland, dat de menschelijke geest er zich gesymboliseerd weet: begrensd, doch met verre uitzichten en met een enkele top om te beklimmen?

10 Maart 1943 